\title{
Interactive Problem-Solving Interventions as Instrument of Conflict Transformation: Prospects and Challenges
}

\author{
DOI http://dx.doi.org/10.4314/mlr.v10i2.6
}

Frew Demeke Alemu *

\begin{abstract}
Even though wars between states were historically the major forms of conflict, civil strife based on questions of identity, ethnicity, religion and other similar grounds has become the order of the day after the end of the Second World War. The complexity of mostly overlapping, social, economic, cultural, political and religious factors in these conflicts makes them difficult to deal with. This structural and conceptual metamorphosis in the international conflict paradigm has required the international community to rethink the traditional and formal conflict management and third party intervention techniques and instruments such as negotiation and mediation. In the course of achieving these goals, conflict scholars have focused on multiple but concurrent multi-track diplomacy instruments. Track II of this multitrack diplomacy and its conflict transformation instruments are based on the concerted efforts of unofficial actors to establish unofficial communication channels and facilitate the relations between the conflicting parties. One of the most commonly used instruments of Track II diplomacy is interactive problem-solving. The primary (but not the only) instrument of interactive problem-solving is a problem-solving workshop. This interdisciplinary comment deals with pertinent issues of relevance with regard to the nature and effectiveness of this conflict transformation instrument. In doing so, it makes a practical effectiveness assessment test against one of such methods, i.e., the Kumi method.
\end{abstract}

\section{Key terms}

Conflict, conflict transformation, multi-track diplomacy, Track II diplomacy, interactive problem-solving, problem-solving workshop, Kumi Method

* Frew Demeke Alemu (LLB, LLM in International Human Rights Law from Lund University, Sweden, MPP in Public Policy and International Conflict Management from Willy Bardt School of Public Policy at the University of Erfurt, Germany); Director of the Research and Resource Centre at the Ethiopian Human Rights Commission. Email: freyoss@yahoo.com 


\section{Introduction}

The face of international conflicts has significantly changed after the Second World War and this has forced the international community to revisit the status quo of conflict management approaches. The traditional conflict management mechanisms that need revisiting include legal methods, peacekeeping, mediation and negotiation. Given the prevalence of inter-state, intra-ethnic and identity based conflicts, it has become an imperative to adopt a more comprehensive and robust third-party conflict intervention techniques. ${ }^{1}$ These mechanisms are designed in a way that enables the international community to deal with the root causes of the prevailing intra-state, ethnic and identity based conflicts by putting the domestic actors at the center of the conflict resolution process. ${ }^{2}$ One of such mechanisms is interactive problem-solving intervention which emphasizes on the close interaction of the conflicting parties through a bottom-up approach.

Some argue that this instrument of conflict intervention is a very effective tool in addressing the root causes of a conflict through facilitating a forum of open and honest dialogue among the members of the different conflicting parties, while others contend that the real impact of such effort is limited to the doors of the conference venue as it involves only a limited number of participants who cannot guarantee the dissemination of the outcomes to the rest of the society. Furthermore, the critiques point to the difficulty of measuring the impact of such efforts in the community and the temporal longevity of impact as the major drawbacks of this intervention method. Hence, this comment evaluates the relevance and effectiveness of this conflict resolution method in solving inter-group conflicts by referring to a modern case study where such method was used.

The first section of the comment is a brief elaboration on the evolution of third-party intervention. The second section briefly discusses Track-II diplomacy in light of interactive problem-solving method, and it highlights the theoretical basis of problem-solving method. The third section deals with problem-solving workshop as a specific method of interactive problem-solving, followed by the last section which briefly presents the Kumi method of interactive problemsolving as an empirical case study.

\footnotetext{
${ }^{1}$ Jacob Bercovitch and Richard Jackson (2012), Conflict Resolution in the Twenty-First Century: Principles, Methods and Approaches, (University of Michigan Press), p. 8.

${ }^{2}$ Ibid.
} 


\section{The Evolution of Third Party Intervention: Emergence of Multi-Track Conflict Resolution Approach}

Similar to other social discourse, the regime of third party intervention in conflict has undergone major stages of metamorphosis. The major transformative step to the discourse took place since the end of the Cold War. The main reason for this change in the framework is the change in the nature of conflicts following that era. Upon the unexpected collapse of the Soviet Union and the end of the bipolar world, there were high hopes for a peaceful world. These hopes mainly emanated from the minimized probability of a third nuclear World War. Expectations were also partially fulfilled through more coordinated international security policies, a sharp decrease in the frequency of interstate wars, and the emergence of the concept of state responsibility towards its citizens and the international community as a whole-as opposed to the traditional conception of strict state sovereignty. ${ }^{3}$ Nevertheless, these hopes for a peaceful world have been shattered by the new faces of conflict. ${ }^{4}$ At present, internal armed conflicts are the major threats to international peace and security.

\subsection{The traditional state-centric approach}

The original approach, which has dominated the regime of third party intervention since its inception, is the state centric Westphalian approach that emphasizes on the concept of state sovereignty. ${ }^{5}$ This regime approached all activities and problems, including conflicts, in the international system from the sole perspective of power politics, i.e., with absolute exclusion of other actors and issues that were not the central concern of states. ${ }^{6}$ This approach seems to have been well-suited for the period before the end of the Cold War as most of the conflicts during this time, including the First and Second World Wars as well as the proxy wars during the Cold War, were characterized by the involvement of formal actors, i.e. states or well defined non-state actors. Hence, the regime of conflict management was greatly influenced or informed by the traditional conflict management mechanisms such as legal methods, peace keeping, mediation and negotiation which put emphasis on maintaining the status quo and state security, rather than justice and human security. ${ }^{7}$ During this era, the actors that were called to the table of conflict management were only states and well-defined insurgents as represented by diplomatic staff, head of states or the military.

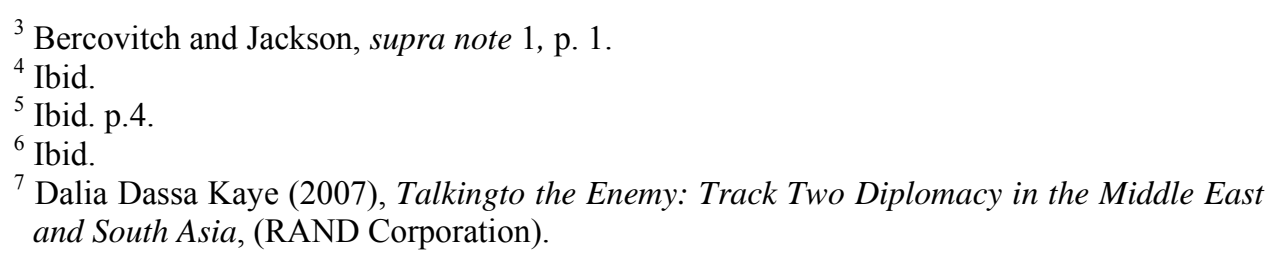




\subsection{The changing faces of conflict and the paradigm shift in the notion of third party intervention}

The changing nature of international conflicts from inter-state to intra-state wars and the resultant structural and conceptual metamorphosis has forced the international community to rethink the existing conflict management and third party intervention techniques and instruments. In the post-Cold War era intrastate conflicts are mainly characterized by a deeply rooted ethnic, religious, communal identity, cultural and resource-driven conflicts. ${ }^{8}$ A majority of these conflicts mainly result from devastating poverty and weak or corrupt governance system, among others. ${ }^{9}$ The complexity of these deadly conflicts that are mostly caused by overlapping social, economic, cultural, political and religious factors make them difficult to deal with. ${ }^{10}$ This has led to the redefinition of international conflict with a view to embracing both intra-state and inter-state wars, thereby resulting in a paradigm shift from conflict management to conflict resolution and conflict transformation ${ }^{11}$

These mechanisms are designed to enable the international community to deal with the root causes of the prevailing intra-state ethnic and identity conflicts. Furthermore, these approaches, unlike the previous one, focus, not only on state security, but also on human security and justice. In doing so, conflict scholars have come up with new goals and approaches that suit the contextual flux in the conflict paradigm. These include the establishment of a just and democratic political order, the promotion of human rights, the creation of an emancipatory political system, reconciliation and truth commissions, international tribunals, and preventive diplomacy and early warning. ${ }^{12}$ In the course of achieving these goals, conflict scholars have focused on multiple but coexisting multi-track diplomacy instruments. This has been found a very sound approach given the opportunity it provides to combine conflict resolution efforts at official and unofficial levels as well as traditional and modern approaches, where appropriate. ${ }^{13}$ Hence, the new concept of multi-track diplomacy can be

\footnotetext{
${ }^{8}$ Rodney L. Petersen (2010), 'Religion and Multi Tuck Diplomacy', (Boston Theological Institute and Boston University School of Theology), p. 528.

${ }^{9}$ Bercovitch and Jackson, supra note 1, p. 2.

${ }^{10}$ Ibid.

${ }^{11}$ Ibid; Though the concrete distinctive meaning of these three phrases is far from agreement in the academia, Ramsbotham, et al have tried to make a fairly agreeable distinction among them as follows; Conflict management refers to the limited settlement and containment of conflict while conflict resolution implies that the deep-rooted sources of conflict are addressed and transformed, and conflict transformation indicates to the deeper level of conflict resolution. For further explanation see, Ramsbotham, et al (2011), The prevention, management and transformation of deadly conflicts (Polity Press).

${ }^{12}$ Id.p.6

${ }^{13}$ Ibid.
} 
taken as a more robust and comprehensive extension of existing state-diplomacy (First Track Diplomacy) rather than a counter concept. ${ }^{14}$

It has to be noted that conflict management is a complex process that encompasses much more than negotiating an end to violence. It includes the prevention of new disagreement and reinstitution of relationships. ${ }^{15}$ Richmond emphasizes this fact, noting that "[T]he new current approaches to conflict resolution have as their goal not just the cessation of violent behaviour but the establishment of new forms of interactions that can reflect the basic tenets of justice, human needs, legitimacy, and equality". ${ }^{16}$ This can only be achieved through the involvement of all stakeholders in the process of dealing with conflict, which needs multiple avenues. The regime of conflict management has thus transformed itself into multi-track arena to respond to this need.

\section{Track II Diplomacy: Interactive Problem-Solving}

\subsection{Core features of interactive problem solving}

As mentioned above, Track II diplomacy is based on the concerted efforts of unofficial actors to establish unofficial communication channels and contribute to the resolution of the conflict. It provides an opportunity to explore opportunities for confidence-building measures and de-escalation of conflict. ${ }^{17}$ Furthermore, it opens a window of opportunity for empowering citizens to participate in decision making processes. ${ }^{18}$ Joseph Montville defines Track II diplomacy as: "unofficial, informal interaction between members of adversary groups or nations which aims to develop strategies, influence public opinion and organize human and material resources in a way that might help resolve their

${ }^{14}$ Daniel Wehrenfennig (2008), 'Multi-Track Diplomacy and Human Security', 7 Human Security Journal, p.81.;To give a brief description of the actors and elements of multitruck diplomacy; Track I Diplomacy implies the effort of conflict management at state or official level; which usually relay on the traditional instruments of conflict management such as negotiation and mediation. Track II Diplomacy refers to the work done by nonelite actors representing non-governmental organizations, mostly with the ultimate purpose of creating an environment of receptivity for Track I activity. This embraces various interactive problem solving methods. Track III Diplomacy refers to "people to people" search for common ground undertaken by individuals or private groups. This type of activity may involve organizing meetings and conferences, generating media exposure, and political and legal advocacy.

${ }^{15}$ Wehrenfennig, Id., p. 82

${ }^{16}$ As cited in Bercovitch and Jackson, supra note 1, p. 9.

${ }^{17}$ Ibid.

18 Ibid. 
conflict". ${ }^{19}$ The major input of this perspective is its objective to influence social constituencies and changing public opinion.

One of the most commonly used instruments of Track II diplomacy is interactive problem-solving. As stated above, the development of interactive problem-solving as an instrument of conflict resolution is part of the evolutionary process in the field after the end of the Cold War. These new instruments focus on addressing deep-rooted and structural issues. ${ }^{20}$ This approach seeks to identify the root-causes of conflict relying on studies of human nature, human behaviour, and social structures. ${ }^{21}$ It employs an intersubjective approach of conflict which includes politics, especially in relation to representation and identity. ${ }^{22}$ Hence, it has brought to light a new approach on human security and the role of states and individuals in world politics. ${ }^{23}$ Accordingly, individuals matter, as do states, and human security is as important as state sovereignty.

\subsection{The theoretical basis of interactive problem solving method}

The theoretical foundation of the interactive problem-solving conflict resolution method was initially laid by John Burton. In developing his theoretical framework, Burton was guided by the principle that the best intervention is mainly about bringing together thoughtful action and reflection, so that action might be continually fine-tuned. ${ }^{24}$ He traced the roots of persistent intergroup conflicts to the frustration of basic human needs. ${ }^{25} \mathrm{He}$ emphasized that a conflict analyst shall distinguish, both at the theoretical and empirical levels, between interests, which are open to negotiation, and needs, which are non-negotiable. ${ }^{26}$ According to Burton, unless identity needs are addressed effectively, the recurrence of intractable conflicts is inevitable. Hence, the role of third-party interactive-problem solving is to channel the parties to a process in which they might come up with creative solutions to address their respective underlying needs and meet them in an interdependent relationship. ${ }^{27}$

19 Joseph Montville (1987), "The Arrow and the Olive Branch: A Case for Track Two Diplomacy in Conflict Resolution: Track Two Diplomacy”, (Washington, DC: U.S. Government Printing Office.

${ }^{20}$ Bercovitch and Jackson, supra note 1, p. 8 .

${ }^{21}$ Id., p. 9.

${ }^{22}$ Ibid.

23 Ibid.

${ }^{24}$ Tamra Pearson d'Estrée (2009), "Problem-Solving Approaches", (in The SAGE Handbook of Conflict Resolution, ed. Jacob Bercovitch et al, Thousand Oaks, CA: Sage) p.13.

${ }^{25}$ John Burton (1969), "Conflict and communication: The Use of Controlled Communication in International Relations” (London: Macmillan,).

${ }^{26}$ Tamra Pearson d'Estrée, supra note 24, p.13.

${ }^{27}$ Ibid. 
Burton's Basic Human Needs Theory was much influenced by Abraham Maslow's 'hierarchy of needs' -which states that human motivation is based on a hierarchy of needs, ordered from basic physical needs to psychological requirements such as recognition, achievement and fulfillment that are depicted as biologically innate. ${ }^{28}$ Burton applied Maslow's hierarchy of needs theory to a conflict context. According to Burton, the list of basic human needs includes not only material needs such as food, shelter, physical safety and well-being, but also psychological needs such as identity, security, autonomy, recognition, selfesteem and a sense of justice. ${ }^{29}$

Burton contends that these psychological needs are even more fundamental than basic physical needs like that of food and shelter, hence people pursue them in one way or another. ${ }^{30} \mathrm{He}$ tells us that "[h]uman needs in individuals and identity groups who are engaged in ethnic and identity struggles are of this fundamental character". ${ }^{31}$ Failure of recognition and denial of identity by a society would certainly lead to alternative behavior designed to pursue and satisfy those needs by all means available, be it ethnic war or any other type of violence. ${ }^{32}$ Burton underscores that "deep-rooted conflicts cannot be contained or suppressed in the long term, but can be prevented or resolved only by the satisfaction of basic needs through conflict resolution". ${ }^{33}$ Hence, Burton's theory indicates that although traditional power theory is correct in hypothesizing conflict over scarce resources, it had the erroneous conclusion that human behavior was determined primarily and solely by material benefits, and that the root causes of conflicts was over competition for scarce resources. ${ }^{34}$ Burton rather points out that human behavior is mostly shaped by deeper concerns of identity and autonomy. ${ }^{35}$

Burton further notes: "A conflict is not resolved merely by reaching agreement between those who appear to be the parties to the dispute. There is a wider social dimension to be taken into account: the establishment of an environment that promotes and institutionalizes value relationships". ${ }^{36}$ Hence, the role of conflict resolution and third-party involvement is to provide an

${ }^{28}$ Ülkü D. Demirdöğen (2011) 'A Social-Psychological Approach to Conflict Resolution: Interactive Problem Solving', 4:1 International Journal of Social Inquiry, p. 220.

${ }^{29}$ John Burton (1990), “Conflict: Resolution and Prevention" (London: Macmillan)

${ }^{30}$ Demirdöğen, supra note 28, p. 220.

${ }^{31}$ Burton, supra note 29, p.36.

${ }^{32}$ Demirdöğen, supra note 28, p. 220.

${ }^{33}$ R. Fisher. (1997), 'Interactive Conflict Resolution', (New York: Syracuse University Press) p.6.

${ }^{34}$ Burton, supra note 29, p. 46.

${ }^{35}$ Tamra Pearson d'Estrée, supra note 24, p.14.

${ }^{36}$ Burton, supra note 29, p. 47. 
opportunity for analysis and the use of this conscious and creative resource. ${ }^{37}$ Methodologically, this theory relies on analytical problem-solving workshops and analytic dialogues in which the roots of conflict and the suppressed human needs of the conflicting parties can be analytically understood. ${ }^{38}$ After the relationships of the parties have been well analyzed and each side is accurately informed of the perception of the other, alternative means of attaining values and goals that might be acceptable to all parties are revealed. ${ }^{39}$

This theme is further stated in the writings of subsequent theorists (Crocker et al., 1999; Kelman, 1999, 2005; Lederach, 1997; Saunders, 2001). In particular, Kelman has further developed Burton's basic human needs approach to conflict resolution by injecting a social-psychological dimension to it. In agreement with Burton, Kelman reiterated that "identity, security and similarly powerful collective needs and the fears and concerns about survival associated with them, are often important causal factors in intergroup and inter-communal conflict" ${ }^{40}$ He further identified the causes of conflict in general to be subjective and objective, which are interrelated. ${ }^{41}$ Conflicts over objective factors, such as territory and/resources imply subjective fear or concern about security and identity. ${ }^{42}$ And mostly conflicts are further fueled by other subjective psychological factors such as misunderstanding and distrust. ${ }^{43}$ In this context Kelman contends that the main parameter for a successful conflict resolution is satisfaction of fundamental needs of the parties concerned. ${ }^{44}$

Extrapolating his social-psychological approach to international conflict, Kelman states that international conflict is not solely about intergovernmental or interstate relations; it is rather an inter-societal process. ${ }^{45}$ Since conflict is inevitable, psychological, cultural and social-structural approaches must be embraced in the analysis and intervention in harmony with military, strategic and diplomatic paradigms. ${ }^{46}$ Kelman gives due emphasis to the importance of multidimensional conflict intervention, including a psycho-social approach:

Overcoming barriers requires the promotion of a different kind of interaction, one that is capable of reversing the conflict dynamics. At the micro-level,

\footnotetext{
${ }^{37}$ Tamra Pearson d'Estrée, supra note 24, p.14.

${ }^{38}$ Demirdöğen, supra note 28, p. 220 .

${ }^{39}$ Ibid.

${ }^{40}$ H. Kelman. "Social-Psychological Dimensions of International Conflict" In I.W. Zartman \& J.L. Rasmussen (Eds.), (1997) 'Peacemaking in International Conflict: Methodsand Techniques' (Washington, D.C.: United States Institute of Peace Press,) p. 195.

${ }^{41}$ Demirdöğen, supra note 28, p. 221.

${ }^{42}$ Ibid.

${ }^{43}$ Ibid.

${ }^{44}$ Ibid.

${ }^{45}$ Ibid.

${ }^{46}$ Ibid.
} 
problem-solving workshops [...] can contribute to this objective by encouraging the parties to penetrate each other's perspective, to differentiate their image of the enemy, to develop a de-escalatory language and ideas for mutual reassurance, and to engage in joint problem solving designed to generate ideas for resolving the conflict that are responsive to the fundamental needs and fears of both sides. At the macro-level, reversal of the conflict dynamic depends on the establishment of a new discourse among the parties, characterized by a shift in emphasis from power politics and threat of coercion to mutual responsiveness, reciprocity, and openness to a new relationship. $^{47}$

\section{Problem-Solving Workshops}

The primary (but not the only) instrument of interactive problem-solving is problem-solving workshop. ${ }^{48}$ It is with the development of this concept that scholars such as Burton and Kelman introduced the idea of 'conflict transformation'. ${ }^{49}$ The major points of divergence between problem-solving workshops and the traditional conflict management methods of official diplomacy, including negotiation and mediation relate to (a) the emphasis by the former on addressing poor relationships between parties; and (b) the latter's assertion that conflict can only be resolved through mutually accepted solutions; and (c) the unofficial small group discussion nature in problem-solving workshops. ${ }^{50}$ Authors such as Ropers labelled this mechanism of dispute resolution as the most ambitious approach, in which the disputants organize their communication in such a way that they are able to systematically work through the substance of their differences. ${ }^{51}$

The typical workshop brings together unofficial representatives of conflicting groups in a private setting for them to engage in face-to-face communication. ${ }^{52}$ This forum of discussion about the conflict is informal, off-the-record and low-

${ }^{47}$ Kelman, supra note 40, p. 233.

${ }^{48}$ Herbert C. Kelman, 'Interactive Problem Solving in Israeli- Palestinian Case: the Past Contribution and Present Challenges'. In R Fischer (2005), Paving the way: Contributions of Interactive Conflict Resolution to Peace Making, (Lamham, MD, Lexington Books) p.5.

${ }^{49}$ Bercovitch and Jackson, supra note 1, p. 9.

${ }^{50}$ Lisa J. Freeman \& Ronald J. Fisher (2012), 'Comparing a Problem-Solving Workshop to a Conflict Assessment Framework: Conflict Analysis Versus Conflict Assessment in Practice', 7:1 Journal of Peace building \& Development, p.68.

51 Norbert Ropers (2003), 'From Resolution to Transformation: The Role of Dialogue Projects', (Berghof Research Center for Constructive Conflict Management) p. 3.

${ }^{52}$ Freeman \& Fisher, supra note 50. 
risk. ${ }^{53}$ The objectives of the workshop include: attitude change, the generation of innovative solutions, and improvement of intergroup relationships. However, these rationales are not taken as the primary and sole end of the conflict resolution process in a given conflict; they are rather intended to provide an alternative but complimentary form of interaction to official peace process that focus on agreements and their implementation. ${ }^{54}$ It is presumed that the betterment of the relationship amongst the unofficial parties will contribute to the resolution of the objective elements of the conflict. ${ }^{55}$ Hence, the ultimate goal is to create an atmosphere for positive interaction between unofficial representatives of opposing parties that enable attitudinal change, and creative problem solving, which serve as an input in the official process and contribute to de-escalation. ${ }^{56}$

Kelman identified three basic rules for the workshop. It must be primarily intended to facilitate the free participation, privacy and confidentiality of the proceedings without the expectation that agreement will be reached. Balanced and equitable interaction among the parties is required. Moreover, participants of the workshop must come as private individuals rather than official representatives. ${ }^{57}$ However, they must be politically involved or must be influential enough, so that they can easily disseminate the results of the workshop to the policy-making machineries of their respective sides. ${ }^{58}$

It is mostly facilitated by skilled and acknowledged third-party academicians, who are knowledgeable about conflict-resolution theories and the region in question. ${ }^{59}$ However, the third party cannot propose a solution or employ leverage, rather only facilitates analysis of the conflict and the creation of possible solutions by creating a spirit of motivation for problem solving. ${ }^{60} \mathrm{~S} / \mathrm{he}$ also regulates the interaction between parties.

\subsection{Steps in Problem-Solving Workshops}

Most workshops generally last for three to five days, and although the agenda is not fixed, a general procedure has emerged. ${ }^{61}$ In most cases the workshop starts

${ }^{53}$ Ibid.

${ }^{54}$ Freeman \& Fisher, supra note 50, p.69.

${ }^{55}$ Ibid.

${ }^{56}$ Ibid.

${ }^{57}$ Kelman, supra note 40, p. 214.

58 Ibid; Kelman states that in the Israeli- Palestinian workshops the participants have included Parliamentarians, leading figures in political parties or former movements, former military officers or government officials, and journalists or editors specialized on the Middle East.

${ }^{59}$ Demirdöğen, supra note 28, p. 222.

${ }^{60}$ Freeman \& Fisher, supra note 50, p. 69.

${ }^{61}$ Ibid. 
with the exchange of views and experiences of the conflict among the participants. This phase is concerned with the formulation of the different point of views of the various parties as clearly as possible and the identification of the substance of the conflict. ${ }^{62}$ Rouhana (1995) calls this phase 'cognitive empathy' -the process by which each party moves from expression of its own needs to comprehension of the needs of the other. ${ }^{63}$ The second phase is called 'responsivity to the needs of others'. This stage involves each party looking for an assurance that the other party does not only understand its needs but also recognizes its legitimacy and takes it into account in the course of developing solutions. ${ }^{64}$ The third phase is about the identification of shared interests and similar needs and fears. ${ }^{65}$ Furthermore, participants build a new group identity and mode of interaction that has the potential to develop ideas thereby contributing to a resolution. ${ }^{66}$ The fourth and final stage is called phase of 'working together.' In this stage, the group discusses ways of implementation of the ideas and also thinks about overcoming the obstacles to possible solutions while identifying the constraints on each side. ${ }^{67}$

\section{Figure 1: Levels of Cooperation in Dialogue Process}

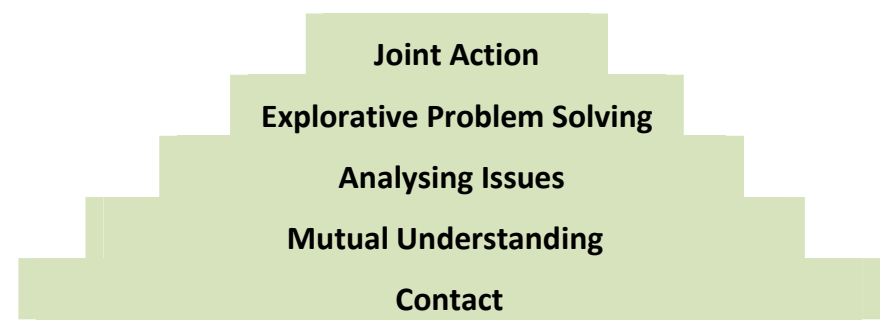

Source: McCarteny 1986

These phases might be completed in a single workshop or may need several consecutive meetings. ${ }^{68}$ This has to be decided by the third party after carefully assessing the readiness of the participants to move from one phase to another. ${ }^{69}$

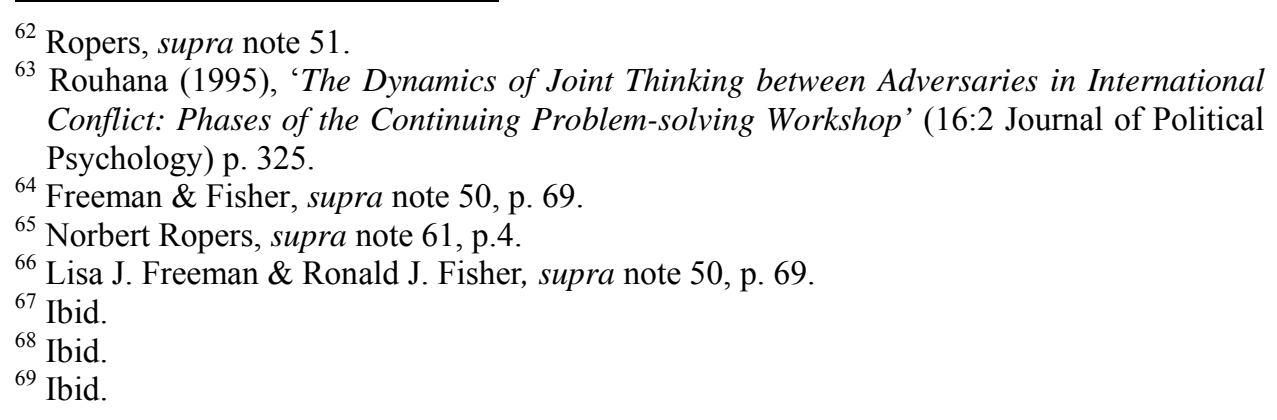




\subsection{The limitations of problem-solving workshop}

From the very beginning, this instrument of conflict intervention has been controversial. The primary limitations that have been raised by many scholars are the issues of relevance and effectiveness. ${ }^{70}$ One of the earliest criticisms in this respect came from Ronald Yalem, who doubted the effectiveness of this methodology given the lack of assurance for transfer of the positive results gained in the workshop room to the society and the absence of concrete criteria of measurement in order to evaluate the actual impact of a given intervention. ${ }^{71}$ He argued that, although such intervention might serve to build trust, it can only be a supplement to traditional methods of conflict resolution. These criticisms have been sustained for long by various scholars and have not yet been effectively addressed by the proponents of the methodology. ${ }^{72}$

Fischer, in his study on evaluation efforts of Interactive Conflict Resolution, found that few systematic and comparative analyses exist although several practitioners claim to have an impact on creating peace in different conflicts around the world. ${ }^{73}$ In their effort to address the limitation of measurability of impact, d'Estrée et al underline that putting in place a framework for evaluation that allows tailoring to the specific emphasis of a process can help in identifying the actual achievement of a conflict resolution scheme. ${ }^{74}$ In this regard, they pointed out two primary challenges that can be encountered in the evaluation of this specific intervention methodology. ${ }^{75}$

The first challenge has to do with the selection of the criteria. The concerns here are: who chooses the criteria for evaluation and on what ground; how can the criteria be contextualized based on actor, purpose and context? The selection of criteria might also be challenging as interventions might have multiple and mostly vague or unstated goals. The second and mostly cited challenge is the issue of linking the micro-changes to the wider and structural, macro-changes inherent in peace-making. The complicated nature of conflicts makes it difficult to pin-point the casual effect of one micro-level intervention on a macro-level. These challenges imply the fact that the theoretical investigation of interactive problem-solving or inter-group conflict management is still poorly developed.

To illustrate these challenges, d'Estrée et al have provided a practical example from the Israel-Palestinian dialogues, which have been considered as

\footnotetext{
${ }^{70}$ Tamra Pearson d'Estrée, supra note 24, p. 18.

${ }^{71}$ R. Yalem, "Controlled communications an conflict resolution”,(8:3 Journal of Peace Research, 1971) p. 266.

${ }^{72}$ Tamra Pearson d'Estrée, supra note 24, p. 18.

${ }^{73}$ Fisher, supra note 33, p.10.

${ }^{74}$ Tamra Pearson d'Estré et al (2001), 'Changing the Debate about "Success" in Conflict Resolution Efforts’, Negotiation Journal, p. 102.

${ }^{75}$ Ibid.
} 
intervention under the broader definition of interactive-problem solving. ${ }^{76}$ Some considered these venues as important milestones to set the stage for peacemaking through creating common understanding of the conflict among the people, while others criticized them for their limited focus. ${ }^{77}$ Practitioners and others intended to come up with criteria to measure the success rate of the dialogue, which has brought to light the difference in perspective on this subject. This lack of agreement on the set of criteria to be used led to confusion and doubt over the entire relevance of the process. ${ }^{78}$

The Israeli-Palestinian dialogues are also good examples of the second limitation, i.e., linking immediate or short term micro-changes to long term, structural, macro-changes. The dialogues mostly took place in informal and closed environments and were structured in ways that they could establish trust and encourage new reflections and learning. Though it is probable that the participants developed a significant amount of trust within the group, the trust between the communities they come from might not be altered at all. In this context, d'Estrée et al ask: what kind of change can one expect as a result of the dialogue? How can the individual or mini-group change be effectively translated into a change in relations at inter-group level? Hence, as many other interactive problem-solving interventions, the Israeli-Palestinian conflict resolution evaluation is also stranded in the usual challenges of definition and criteria for success and the linkage between micro-and macro-level changes. ${ }^{79}$

\section{Case Study: The Kumi Method}

The meaning of the word Kumi is 'rise up' in both Arabic and Hebrew. ${ }^{80}$ It is one method of interactive problem-solving in a workshop setting. Kumi is a method of conflict intervention enabling innovative social change through conflict transformation. ${ }^{81}$ In other words, it is a mechanism that can be adopted by individuals and groups who work towards social and political reengineering so that they can reflect upon the root causes of the conflicts they are involved in and collectively march towards creative alternative solutions. ${ }^{82}$

\footnotetext{
${ }^{76}$ Fisher, supra note 43.

${ }^{77}$ Tamra Pearson d'Estré et al, supra note 90.

${ }^{78}$ Ibid.

${ }^{79}$ Ibid.

${ }^{80}$ A Hand Book for practitioners, 'Building Networks of Kumi Learners in Europe: Working across geographic and cultural boundaries on issues of Islamophobia and migration', (Education and Culture Lifelong Learning Program, 2013), p. 6.

${ }^{81}$ Ibid.

${ }^{82}$ Transform, 'The Kumi Method: An Introduction' (2013), The Interdisciplinary Center for Conflict Analysis, Political Development and World Society Research), p. 1.
} 


\subsection{The Metamorphosis of Kumi}

The Kumi method was developed by a group of diverse scholars who shared a common sense of frustration over the sluggish progress and impact of IsraeliPalestine people-to-people programs. ${ }^{83}$ After a long period of research on the way in which such programs were carried out, it was concluded that there were important flaws in the basic architecture and implementation of most of the programs which could be linked with their general understanding of conflict. ${ }^{84}$ Since these programs primarily focused on staging dialogue between the conflicting parties, sometimes they presumed that the causes of the conflict mainly lay in the perception of individuals which could be solved by facilitating contact for people from both sides. ${ }^{85}$ What this approach mainly missed was the recognition of the deeply-rooted social structures which were fuelling the Israeli-Palestine conflict. These range from power asymmetry between the two societies to the bigger geopolitical picture. ${ }^{86}$ This had led to the superficial remedy of issues of identity. ${ }^{87}$

From the findings of the researches, it was deduced that for such initiatives to be fruitful, a new approach that would empower grassroots organizations and mid-level political leaders was needed for them to effectively challenge the bigger social structure perpetuating conflict ${ }^{88} \mathrm{~A}$ method was needed to put this approach on the ground. In order to achieve this goal, a coalition was created between three organizations: Transform (the Interdisciplinary Centre for Conflict Analysis, Political Development and World Society Research), IICP (Institute for Integrative Conflict Transformation and Peace building) and ICA (Institute for Cultural Affairs). ${ }^{89}$ Each of them has its own approach of addressing conflict resolution and political organization. ${ }^{90}$ The purpose of the coalition was to formulate a hybrid of these different methods and perspectives, so that it can be utilized to harness the efforts of grassroots organizations and mid-level societal leadership working in a conflict situation. ${ }^{91}$ The final product of this effort was Kumi which has been further developed while it was put to use in years 2009-2010 in the context of the Israeli-Palestinian conflict. ${ }^{92}$

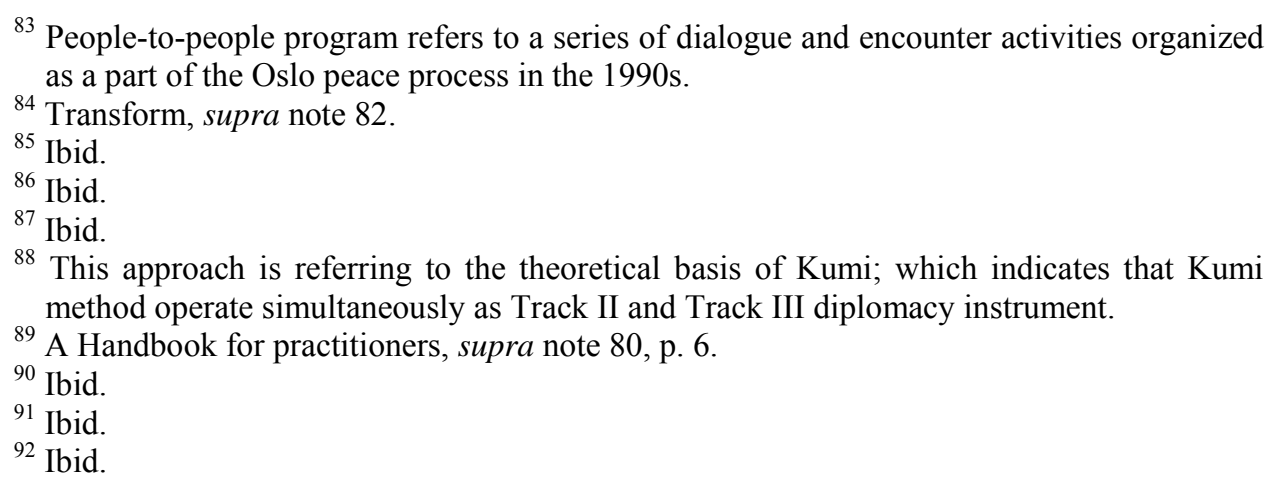




\subsection{Fundamentals of the Kumi Method}

Unlike other problem-solving instruments emphasizing on mere face to face dialogue, Kumi targets the transformation of notions of identity based on exclusion through systematic streaming of the societies' thinking and action towards a set of goals extending beyond the end of the workshop. Hence, the fundamental goal of Kumi is to enable creative social change through conflict transformation or creative conflict transformation through social change. ${ }^{93} \mathrm{Kumi}$ pays great attention to the collective will of a group in order to make change happen. The Kumi process enables individuals and groups to work towards social and political change to reflect on the root causes and the social contexts of the conflicts in which they are involved.

Furthermore, unlike other mainstream people-to-people dialogue projects, this method emphasizes on the creative capacity of the grassroots and mid-level politicians, not just as accessories to official leaders, but as the main parties in demanding and creating socially-just peace. ${ }^{94}$ This enables Kumi to simultaneously operate at different levels of the society. ${ }^{95}$

The method is usually applied in workshops settings that are organized by Kumi practitioners, who work with different conflicting groups over an extended period of time. The process involves a well-organized preparation and follow-up after re-entry. ${ }^{96}$ The ideal transformative ${ }^{97}$ end of the method is that participants will agree on a shared value reflected through concrete steps forward, collective action plans to which they commit themselves.

\subsection{Structure of Kumi Workshop}

Like any other interactive problem-solving workshop, participants in a Kumi workshop pass through different steps. These steps allow participants to engage in conflict analysis in order to (a) explore social and political failures that are inherent to intractable social conflicts; and (b) develop new awareness of reality to be attained in which negative stereotypes and antagonism are replaced by analytical empathy which facilitates transformative politics in which power over

93 Ibid.

${ }^{94}$ Transform, supra note 82, p. 4.

95 This is one of the primary purpose of the method; which has been elaborated in the Kumi Hand Book as follows; "Kumi endorses a multi-track approach in order to contribute to the potentials of significant change across all dimensions of societal structures, cultures and politics in a complementary manner. Working in parallel on the level of grassroots and on the level of mid-level leadership in society increases the potential for creating impact on the ongoing conflict discourse and broadens the awareness of creative new approaches to the conflict that address the needs of all sides involved." P. 10.

${ }^{96}$ Ibid.

${ }^{97}$ According to the developers of this method, true transformation of conflict means distributing power more broadly within society. 
is replaced by power with/for. ${ }^{98}$ These steps enable the participants to effectively deal with different aspects of the conflict in a sequential manner in which each step builds on the results obtained in the previous one. These steps are:

i. Preparation: This involves identification of the target group and establishing contact; researching divisive issues and together with the target group, determining where, how and on what issues the workshop shall focus. ${ }^{99}$

ii. Developing focus, context check and identification of contradictions: In this stage, the issues of focus are identified and the facilitator makes sure that all the participants have general understanding of the issues to be raised in the workshop. ${ }^{100}$ This enables the participants to put their goals on the discussion table and identify the contradictory goals. ${ }^{101}$

iii. Dealing with the conflict in depth: conflict analysis, antagonism and resonance, transcendence: After the identification of contradictory goals, the group directly deals with the central themes of the conflict. Participants deal with identities, and bring to light grievances and antagonisms. ${ }^{102}$ They then deal with the conflict in a more analytical manner. After establishing a common understanding through critical analysis, they reframe the initial goals so that they can open a new avenue for transcending contradictions. ${ }^{103}$

iv. Participatory strategic planning: After achieving a common goal, participants identify a common practical vision depicting the ideal environment they would like to see in 5-8 years. ${ }^{104}$ In this process, obstacles are identified, strategies are developed and detailed action plans are prepared on how to work together for conflict transformation. ${ }^{105}$

v. Supporting implementation upon re-entry: After the workshop, the facilitators continue tracking the progress made by the group and offer practical help while the group begins implementing its action. ${ }^{106}$

What has to be noted in the implementation of these steps is that it might not be a smooth process. Sometimes, facilitators might be bound to repeat steps or interrupt and proceed some other time in a situation where people are not yet ready. Furthermore, there is no guarantee of success, and people might fail to come up with a solution.

\footnotetext{
${ }^{98}$ A Handbook for practitioners, supra note 80, p. 11.

${ }^{99}$ Transform, supra note 82, p. 5 .

${ }^{100}$ Ibid

${ }^{101}$ Ibid.

102 Ibid

103 Ibid.

${ }^{104}$ Ibid.

105 Ibid.

106 Id., p. 6.
} 


\subsection{Evaluation of the Kumi Method}

As already mentioned, Kumi does not end the conflict transformation effort inside the workshop room; it rather tries to extend the achievements obtained to the real world through action oriented planning and networking the participants. Hence, this makes Kumi a bit different from other dialogue projects. However, even though the developers of this method claim that it has remedied the weak sides of other interactive problem-solving mechanisms, it still suffers from the same problem of evaluation and micro-macro change linkage in addition to lack of clear criteria for selection of workshop participants, especially at grassroots levels.

Evaluation of result is a very difficult task in Kumi because we cannot see the actual changes that are brought about in a given community as this may take years or even a decade. Moreover, there is uncertainty as to who chooses the criteria for evaluation and on what ground and how the criteria can be contextualized based on actor, purpose and context. Moreover, the issue of linking the micro-changes to (the wider and structural) macro-changes inherent in peacemaking arises in Kumi context. It is also difficult to establish causal link between the action and the results/changes.

Although Kumi seems to be different (in that it continues tracking the progress made by the group and offers practical help while the group begins implementing its action), given the very weak community networking system in developing countries, especially in conflict areas, it may not be feasible to track down and work with the participants after re-entry. Given the budget constraints and the probable lack of interest on the part of the donors to finance such projects, a question arises whether planning to support implementation after reentry is attainable.

\section{Conclusion}

The nature and cause of conflicts have been dramatically transformed from the mid-1950s'. Civil strife based on questions of identity, ethnicity, religion and other similar grounds -strongly tied to the emotions and the person of individuals and communities- have become the order of the day. Unlike the 'old conflicts' grounded on questions such as sovereignty, territory or political economy, these 'new conflicts' need creative solutions that can address the root causes for a sustainable peace to happen. It is with this view that the regime of third party intervention has undergone a complete evolution from the traditional peace-making mechanisms such as negotiation and mediation, to the multi-track and multidimensional third-party conflict intervention techniques. One of the by-products of this evolution is interactive problem-solving instrument, mostly categorized as Track II diplomacy. 
Scholars such as Burton and Kelman have applauded this mechanism as an efficient and effective method of intervention to address the root causes of protracted identity conflicts. This method is firmly grounded on the human security and basic needs approaches; and these questions mostly lie behind conflicts of identity, ethnicity and culture. Hence, the channel of face-to-face communication facilitated by these interactive problem-solving techniques will open an opportunity for the parties to communicate with each other, and to analyze and work out their conflicts by clearly exposing the grounds of contradiction.

However, other scholars doubt the effectiveness and relevance of this methodology -and rightly so, given its inherent nature and the related difficulty of evaluating impact, and the lack of efficient mechanisms to link the microresults obtained at group level to macro-level outcomes. Hence, as long as these problems are not addressed properly, it will be difficult to use this methodology as effective third-party conflict intervention instrument.

Yet, the discourse on interactive problem-solving interventions has validly revealed that current conflicts are mostly attributable to questions of identity, ethnicity, religion and other similar grounds, and have greater complexity than the traditional wars between states. Conflicts that involve sense of identity, belief and emotions of individuals and communities should thus be addressed through means that accompany (and go beyond) traditional conflict management schemes. Unfortunately however, we are at a juncture whereby the traditional methods seem to be limited in scope in addressing current conflicts, while the new modalities of conflict transformation are yet in the making. This calls for enhanced empathy, creativity, critical thinking and reason on the part of communities, political actors and parties in conflict. 